\title{
Reconfiguring Business Process for Enterprise Information System Based on UML and Polychromatic Sets
}

\author{
Xinqin Gao, Zongbin Li, Liping Zhao, and Yiyong Yao \\ School of Mechanical Engineering, Xi'an Jiaotong University, Xi' an \\ 710049 , China \\ gaoxinqin@yahoo.com.cn, \{lzb9910, lipingzh, yyyao\}@mail.xjtu.edu.cn, \\ WWW home page: http://www.xjtu.edu.cn/en/academics\&research/me.htm
}

\begin{abstract}
Reconfigurability is one of the intelligent characteristics of enterprise information system. It is also a key factor that influences an enterprise to response to market changes and wins a global competition. In this paper, business process reconfiguration for enterprise information system is studied to support the rapid changes in business environment. Firstly, UML and polychromatic sets are united based on their advantages and disadvantages, and a business process reconfiguration method is proposed. Secondly, the main contents of business process reconfiguration for enterprise information system are detailed, which includes the model of business process based on UML, the translation from UML activity diagram to PS contour matrix model, the analysis and reconfiguration of business process and the implement of information system. Finally, an enterprise information subsystem of spare parts requisition is provided for application and validation of the proposed method.
\end{abstract}

\section{Introduction}

Under the environment of economic globalization, modern enterprises face the various changes from themselves and outside. In order to win the competition, enterprises must have ability to reconfigure their business process to adapt themselves to such changes [1]. However, traditional enterprise information systems are developed according to the special industries, special market environments, and special business process [2]. If the customer requirement and business process happen to change drastically, the quondam information system doesn't work

Please use the following format when citing this chapter:

Gao, X., Li, Z., Zhao, L., Yao, Y., 2006, in International Federation for Information Processing, Volume 205, Rescarch and Practical Issucs of Enterprisc Information Systems, cds. Tjoa, A.M., Xu, L., Chaudhry, S., (Boston:Springer), pp.371-381. 
normally. Therefore, enterprise information system that supports business process and business rule must have the reconfigurability to response to market changes [3].

In 1993, Hammer and Champy first proposed the concept of business process reengineering (BPR). They defined business process reengineering as the fundamental rethinking and radical redesign of business processes to achieve dramatic improvements in critical contemporary measures of performance such as costs, quality, speed, and service [4]. Business process reconfiguration is regarded as a revolution of development of enterprise information system and can reduce the cost and improve efficiency remarkably [5].

There are many business process reconfiguration methods for enterprise information system, such as Petri net, UML and IDEF [6-9]. Each method has its own advantages and disadvantages. Generally speaking, these methods can be classified into two types: the formal method and the graphical method. The formal method is precise and its model is easy to realize in computer language. But it is difficult to understand and read for non-specialists. The graphical method is explicit and its model facilitates the description of business process. A wide range of software packages and tools support the development of graphical model. However, the graphical method lacks of accuracy and preciseness.

Enterprise business process is highly dynamic and distributed. A formal but easyto-understand method is needed for reconfiguring business process for enterprise information system. In this paper, we present a business process reconfiguration method based on UML and polychromatic sets (PS) theory. For non-specialists, this integrated method is the graphical representation and easy to understand and popularize. Moreover, it has the firm mathematical foundation and the abundance of analysis methods.

\section{Business process reconfiguration method}

The key idea of polychromatic sets theory is to utilize standardized mathematical model to simulate different objects, such as product, design process, manufacturing process and manufacturing systems [10-13]. Polychromatic sets theory has the significant progress and advantage in problem formalization [11]. However, if polychromatic sets theory is used directly to model the real system, the application developer must have profound field knowledge.

Unified modeling language (UML) is universally acknowledged as an international standard in the software industry and convenient for transition from UML model to program coding (such as Java and $\mathrm{C}++$ ) [14]. Yet, UML is not a formal modeling language. It suffers from a lack of precise syntax and semantics [15]. The model defined by UML is lack of the rigorous, effective verification and analysis. The model cannot be simulated until it is realized, and its modification and improvement are difficult to accomplish.

Based on their advantages and disadvantages, we propose a new business process reconfiguration method, which unites UML and polychromatic sets theory and has a 
well-defined mathematical foundation and an easy-to-understand graphical feature. As shown in Fig. 1, the business process reconfiguration method contains four primary steps as follows:

Step 1. The visual modeling stage based on UML. According to the business requirements, basic model primitives and basic model constructs of UML activity diagram are used to describe and design the business process and UML activity diagram model is established.

Step 2. The mapping stage from UML activity diagram to PS contour matrix. The goal of transformation UML activity diagram model into PS contour matrix model is to analyze and modifying the UML activity diagram model.

Step 3. The analyzing and reconfiguring stage based on PS. With the rigorous mathematics foundation, polychromatic sets theory has power to analyze and reconfigure the business process formally. UML activity diagram model is modified and improved on the basis of analysis results.

Step 4. The implementing stage in computer programming language. The modified UML activity diagram model is implemented in Java or $\mathrm{C}++$ and the information system is developed.

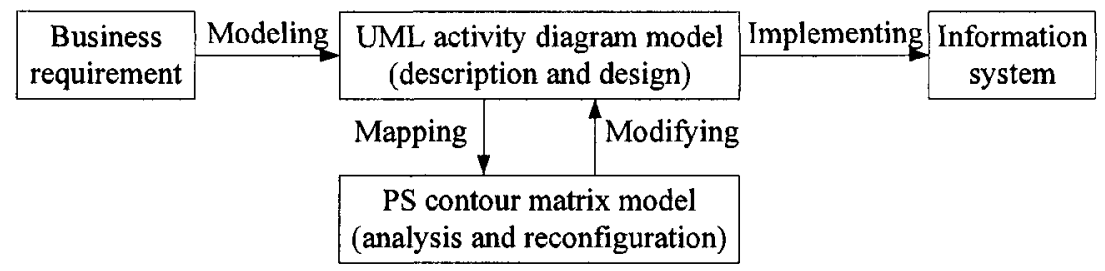

Fig. 1. Business process reconfiguration method

\section{Business Process Reconfiguration for Enterprise Information System}

\subsection{Model of Business Process Based on UML}

Unified modeling language (UML) is not limited to software development. Some of UML views can be used in enterprise modeling, business engineering, and process analysis and system configuration [16]. UML activity diagram can be applied in business process reconfiguration for enterprise information system. It has powerful capability to describe the activity execution sequences of business process and express the basic model constructs: sequence, parallel, choice and iteration. 
Table 1. Basic Model Primitives of UML Activity Diagram

\begin{tabular}{cccc}
\hline \multicolumn{2}{c}{ Nodes } & & \multicolumn{3}{c}{ Interrelations } \\
\hline Start node End node Activity node & Link arc And-split And-join Or-split Or-join \\
\hline
\end{tabular}

\subsubsection{Basic Model Primitives}

UML activity diagram has two kinds of basic model primitives, as shown in Table 1.

(1) Nodes: start node, end node and activity node.

(2) Interrelations: link arc, and-split, and-join, or-split, and or-join.

\subsubsection{Basic Model Constructs}

The above basic model primitives of UML activity diagram can constitute four basic model constructs, as shown in Table 2 . The basic model primitives and basic model constructs of UML activity diagram can constitute any complicated business process model.

\subsection{Translation from UML to Polychromatic Sets}

In UML activity diagram, basic model primitives are nodes and interrelations. The combinations of any two nodes $\left(a_{\mathrm{i}}, a_{\mathrm{j}}\right)$ are recognized as the elements of PS and the interrelations between the any two nodes $F_{\mathrm{k}}\left(a_{\mathrm{i}}, a_{\mathrm{j}}\right)$ are recognized as the contour of PS. The PS contour matrix model $[(A \times A) \times F(A)]$ is established as shown in Fig. 2 . Where, $a_{\mathrm{i}}, a_{\mathrm{j}} \in A .(A \times A)$ is Cartesian product of the nodes set $A$ and itself. $F(A)=\left(F_{1}\right.$, $\left.F_{2}, F_{3}, F_{4}, F_{5}\right)$ are all possible interrelations between the any two nodes. These are link arc, and-split, and-join, or-split and or-join. 


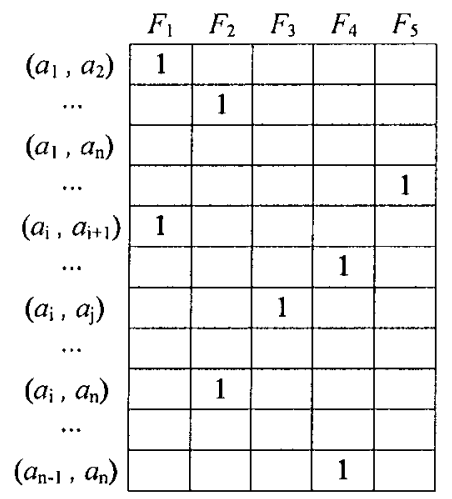

Fig. 2. PS contour matrix model

\subsubsection{Interrelations Rules}

(1) If $F\left(a_{i}, a_{j}\right)=1$, the interrelation exists between the node $a_{\mathrm{i}}$ and the node $a_{\mathrm{j}}$.

(2) If $F_{1}\left(a_{\mathrm{i}}, a_{\mathrm{j}}\right)=1$, the interrelation of the node $a_{\mathrm{i}}$ and the node $a_{\mathrm{j}}$ is link arc.

(3) If $F_{2}\left(a_{\mathrm{i}}, a_{\mathrm{j}}\right)=1$, the interrelation of the node $a_{\mathrm{i}}$ and the node $a_{\mathrm{j}}$ is and-split.

(4) If $F_{3}\left(a_{1}, a_{\mathrm{j}}\right)=1$, the interrelation of the node $a_{\mathrm{i}}$ and the node $a_{\mathrm{j}}$ is and-join.

(5) If $F_{4}\left(a_{1}, a_{j}\right)=1$, the interrelation of the node $a_{\mathrm{i}}$ and the node $a_{\mathrm{j}}$ is or-split.

(6) If $F_{5}\left(a_{i}, a_{\mathrm{j}}\right)=1$, the interrelation of the node $a_{\mathrm{i}}$ and the node $a_{\mathrm{j}}$ is or-join.

\subsubsection{Constructs Rules}

(1) If $F_{1}\left(a_{\mathrm{i}}, a_{\mathrm{j}}\right)=1$, the node $a_{\mathrm{i}}$ and the node $a_{\mathrm{j}}$ constitute sequential construct.

(2) If $F_{2}\left(a_{\mathrm{p}}, a_{\mathrm{i}}\right) \wedge F_{3}\left(a_{\mathrm{i}}, a_{\mathrm{q}}\right) \wedge F_{2}\left(a_{\mathrm{p}}, a_{\mathrm{j}}\right) \wedge F_{3}\left(a_{\mathrm{j}}, a_{\mathrm{q}}\right)=1$, the node $a_{\mathrm{i}}$ and the node $a_{\mathrm{j}}$ constitute parallel construct.

(3) If $F_{4}\left(a_{\mathrm{p}}, a_{\mathrm{i}}\right) \wedge F_{5}\left(a_{\mathrm{i}}, a_{\mathrm{q}}\right) \wedge F_{4}\left(a_{\mathrm{p}}, a_{\mathrm{j}}\right) \wedge F_{5}\left(a_{\mathrm{j}}, a_{\mathrm{q}}\right)=1$, the node $a_{\mathrm{j}}$ and the node $a_{\mathrm{j}}$ constitute choice construct.

(4) If $F_{4}\left(a_{i}, a_{\mathrm{j}}\right) \wedge F_{5}\left(a_{\mathrm{j}}, a_{\mathrm{i}}\right)=1$, the node $a_{\mathrm{i}}$ and the node $a_{\mathrm{j}}$ constitute iterative construct.

Table 2 shows four basic model constructs of UML activity diagram and their PS contour matrix modes. 
Table 2. Basic Model Constructs and Their PS Contour Matrix Models

\begin{tabular}{|c|c|c|c|c|c|c|c|}
\hline $\begin{array}{l}\text { Basic model } \\
\text { constructs }\end{array}$ & UML activity diagram & \multicolumn{6}{|c|}{ PS contour matrix } \\
\hline \multirow{2}{*}{$\begin{array}{l}\text { Sequential } \\
\text { construct }\end{array}$} & & \multicolumn{2}{|r|}{$F_{1}$} & $F_{2}$ & $F_{3}$ & $F_{4}$ & $F_{\mathrm{s}}$ \\
\hline & & $\left(a_{i}, a_{j}\right)$ & 1 & & & & \\
\hline \multirow{5}{*}{$\begin{array}{l}\text { Parallel } \\
\text { construct }\end{array}$} & & \multirow{5}{*}{$\begin{array}{l}\left(a_{\mathrm{p}}, a_{\mathrm{i}}\right) \\
\left(a_{\mathrm{j}}, a_{\mathrm{q}}\right) \\
\left(a_{\mathrm{p}}, a_{\mathrm{j}}\right) \\
\left(a_{\mathrm{j}}, a_{\mathrm{q}}\right)\end{array}$} & $F_{1}$ & $F_{2}$ & $F_{3}$ & $F_{4}$ & $F_{5}$ \\
\hline & & & & 1 & & & \\
\hline & & & & & 1 & & \\
\hline & & & & 1 & & & \\
\hline & & & & & 1 & & \\
\hline \multirow{5}{*}{$\begin{array}{l}\text { Choice } \\
\text { construct }\end{array}$} & & \multicolumn{2}{|r|}{$F_{1}$} & $F_{2}$ & $F_{3}$ & $F_{4}$ & $F_{5}$ \\
\hline & & $\left(a_{\mathrm{p}}, a_{\mathrm{i}}\right)$ & & & & 1 & \\
\hline & & $\left(a_{1}, a_{\mathrm{q}}\right)$ & & & & & 1 \\
\hline & & $\left(a_{\mathrm{p}}, a_{\mathrm{j}}\right)$ & & & & 1 & \\
\hline & & $\left(a_{\mathrm{j}}, a_{\mathrm{q}}\right)$ & & & & & 1 \\
\hline \multirow{3}{*}{$\begin{array}{l}\text { Iterative } \\
\text { construct }\end{array}$} & & \multirow{3}{*}{$\begin{array}{l}\left(a_{1}, a_{1}\right) \\
\left(a_{1}, a_{1}\right)\end{array}$} & $F_{1}$ & $F_{2}$ & $F_{3}$ & $F_{4}$ & $F_{5}$ \\
\hline & & & & & & 1 & \\
\hline & & & & & & & 1 \\
\hline
\end{tabular}

\subsection{Analysis and Reconfiguration of Business Process}

PS contour matrix model not only describes whether the interrelation exists in any two nodes of UML activity diagram, but also represents concrete kind of interrelation existing in any connected two nodes. Further, PS contour matrix can be extended without limit to describe any complex business process. With PS theory operational ability and existing algorithm, the business process model can be analyzed and reconfigured formally. Fig. 3 shows the path-searching algorithm of business process mode. Using this algorithm, all possible activity paths can be found out and the business process can be analyzed, improved and reconfigured. 


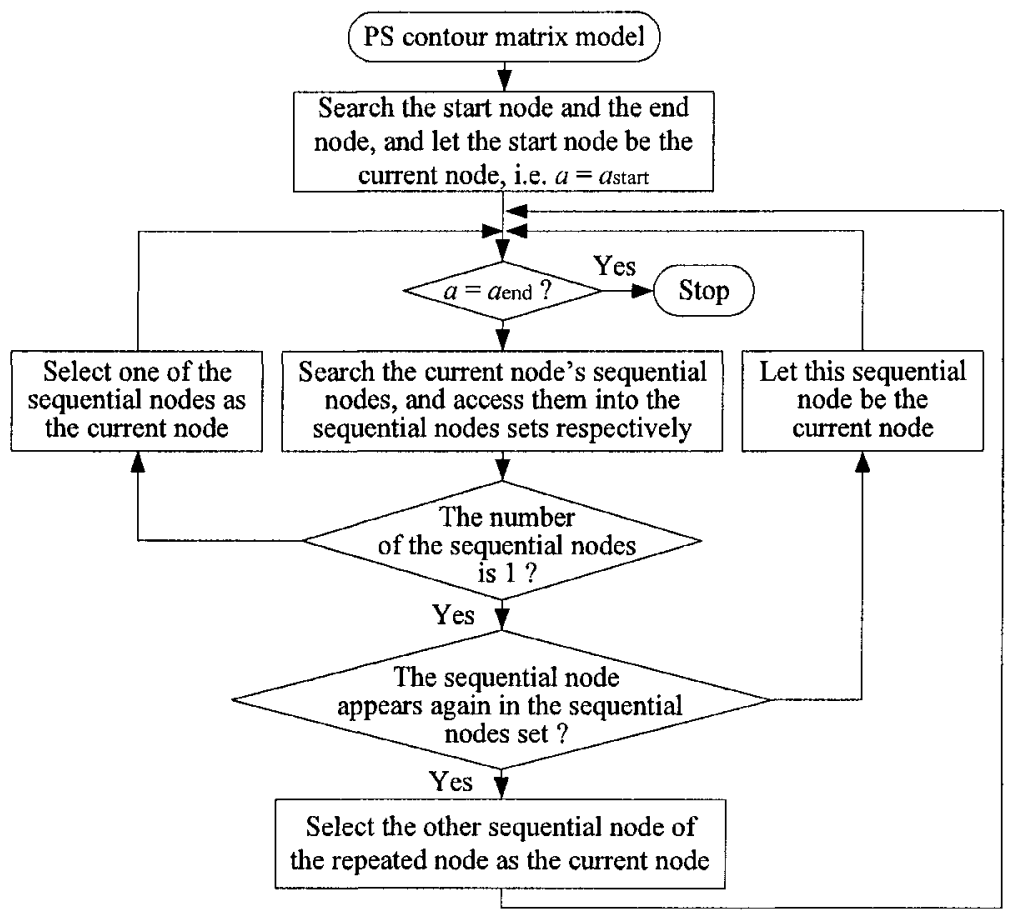

Fig. 3. Path searching algorithm of business process model

\section{A Case Study}

An enterprise information subsystem of spare parts requisition is used to illustrate the effectiveness of the proposed method [17]. Fig. 4 shows UML activity diagram of the spare parts requisition. The meanings of the activities codes are shown in Table 3.

Table 3. Meanings of the Activity Codes

\begin{tabular}{cc|c|cc}
\hline Activity $a_{\mathrm{i}}$ & Meanings of activities & & Activity $a_{\mathrm{i}}$ & Meanings of activities \\
\cline { 1 - 2 } \cline { 4 - 6 }$a_{1}$ & The start node & $a_{7}$ & Inquiring market information \\
$a_{2}$ & Filling in requisition & & $a_{8}$ & Virtual node \\
$a_{3}$ & Examining requisition & & $a_{9}$ & Approving requisition \\
$a_{4}$ & Virtual node & & $a_{10}$ & Creating purchase document \\
$a_{5}$ & Filling in specific requisition & & $a_{11}$ & The end node \\
$a_{6}$ & Collecting requisitions & & & \\
\hline
\end{tabular}

(1) According to the interrelations rules and constructs rules, UML activity diagram is mapped into PS contour matrix model, as shown in Fig. 5. 

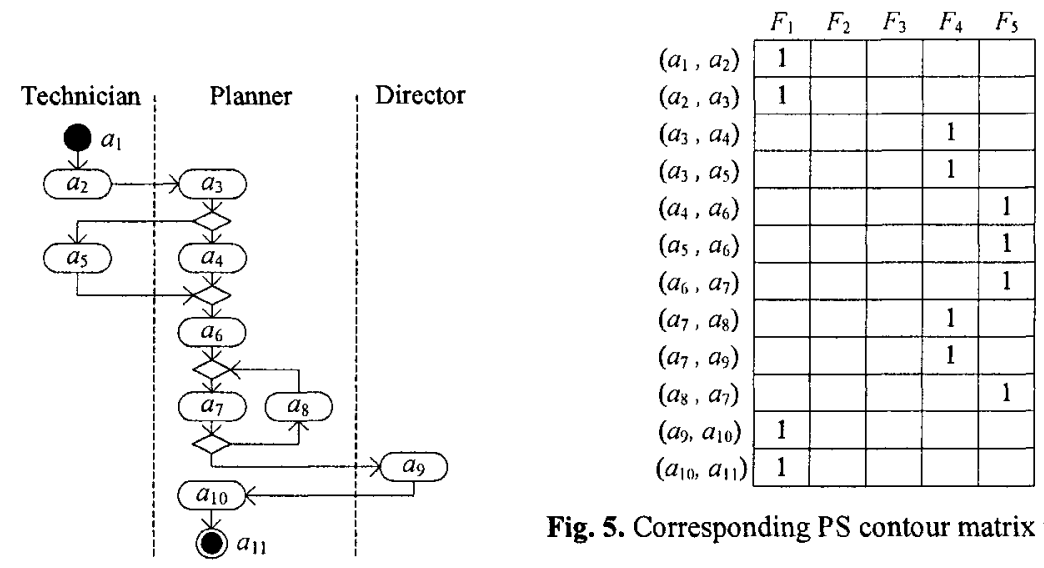

Fig. 4. UML activity diagram model

Fig. 5. Corresponding PS contour matrix mode

(2) Using the path-searching algorithm of business process mode, four activity paths are found out as follows:

$$
\begin{aligned}
& P_{1}=\left\{a_{1}, a_{2}, a_{3}, a_{4}, a_{6}, a_{7}, a_{9}, a_{10}, a_{11}\right\} ; \\
& P_{2}=\left\{a_{1}, a_{2}, a_{3}, a_{5}, a_{6}, a_{7}, a_{9}, a_{10}, a_{11}\right\} ; \\
& P_{3}=\left\{a_{1}, a_{2}, a_{3}, a_{4}, a_{6}, a_{7}, a_{8}, a_{7}, a_{9}, a_{10}, a_{11}\right\} ; \\
& P_{4}=\left\{a_{1}, a_{2}, a_{3}, a_{5}, a_{6}, a_{7}, a_{8}, a_{7}, a_{9}, a_{10}, a_{11}\right\} .
\end{aligned}
$$

(3) Determination of the time consuming of all activities, the execution

\begin{tabular}{|c|c|c|c|c|c|c|}
\hline $\begin{array}{c}\text { Activity } \\
a_{\mathrm{i}}\end{array}$ & $\begin{array}{c}\text { Time } \\
\text { consuming } \\
t_{\mathrm{i}}\end{array}$ & $\begin{array}{l}\text { Interrelation } \\
\qquad F_{\mathrm{k}}\left(a_{\mathrm{j}}, a_{\mathrm{j}}\right)\end{array}$ & $\begin{array}{c}\text { Execution } \\
\text { probability } \\
m_{\mathrm{ij}}\end{array}$ & $\begin{array}{c}\text { Path } \\
P_{\mathrm{v}}\end{array}$ & $\begin{array}{c}\text { Anticipant } \\
\text { time } \\
\text { consuming } \\
T_{\mathrm{v}}\end{array}$ & $\begin{array}{c}\text { Anticipant } \\
\text { execution } \\
\text { probability } \\
p_{v}\end{array}$ \\
\hline$a_{1}$ & 0 & \multirow{3}{*}{$F_{4}\left(a_{3}, a_{4}\right)$} & \multirow{4}{*}{0.9} & \multirow{4}{*}{$P_{1}$} & \multirow{4}{*}{56} & \multirow{3}{*}{0.27} \\
\hline$a_{2}$ & 10 & & & & & \\
\hline$a_{3}$ & 10 & & & & & \\
\hline$a_{4}$ & 0 & \multirow{3}{*}{$F_{4}\left(a_{3}, a_{5}\right)$} & & & & \multirow{3}{*}{0.03} \\
\hline$a_{5}$ & 5 & & \multirow[t]{3}{*}{0.1} & \multirow[t]{3}{*}{$P_{2}$} & \multirow[t]{3}{*}{61} & \\
\hline$a_{6}$ & 16 & & & & & \\
\hline$a_{7}$ & 8 & \multirow{3}{*}{$F_{4}\left(a_{7}, a_{8}\right)$} & & & & \multirow{3}{*}{0.63} \\
\hline$a_{8}$ & 0 & & \multirow[t]{2}{*}{0.7} & \multirow[t]{2}{*}{$P_{3}$} & \multirow[t]{2}{*}{64} & \\
\hline$a_{9}$ & 4 & & & & & \\
\hline $\begin{array}{l}a_{10} \\
a_{11}\end{array}$ & $\begin{array}{l}8 \\
0\end{array}$ & $F_{4}\left(a_{7}, a_{9}\right)$ & 0.3 & $P_{4}$ & 69 & 0.07 \\
\hline
\end{tabular}
probability of the split link and the time consuming of all activity paths as shown in Table 4.

Table 4. Computing Results of Parameters 
The anticipant time consuming of business process is computed as follows:

$$
Z_{1}=\sum_{\nu=1}^{4} T_{v} p_{\nu}=(56 \times 0.27+61 \times 0.03+64 \times 0.63+69 \times 0.07)=62.1
$$

(4) Analysis of the business process and identification of improvement opportunities.

In Fig. 4 and Fig. 5, the planner needs to enquire market information repeatedly, until the parts parameters meet the technician's requirements. The computer suggests that the operator should reconfigure the process. The market information of parts is classified into two kinds of catalogues, namely the generic parts catalogue and the specific parts catalogue. The technician enquires directly the parts catalogue accessed in database. This reconfiguration avoids the negotiations between the planner and the technician.

(5) Modification of the UML activity diagram model and repetition of the procedure from (1) to (3).

Fig. 6 and Fig. 7 show UML activity diagram model after modifying and its PS contour matrix model. In Fig. 6, the meanings of the activities codes are shown in Table 5.

Table 5. Meanings of the Activity Codes after BPR

\begin{tabular}{|c|c|c|c|}
\hline Activity $a_{\mathrm{f}}$ & Meanings of activities & Activity $a_{\mathrm{t}}$ & Meanings of activities \\
\hline$a_{1}$ & The start node & $a_{5}$ & Approving requisition \\
\hline$a_{2}$ & Filling in generic requisition & $a_{6}$ & Creating purchase documen \\
\hline$a_{3}$ & Filling in specific requisition & $a_{7}$ & The end node \\
\hline$a_{4}$ & Collecting requisitions & & \\
\hline
\end{tabular}

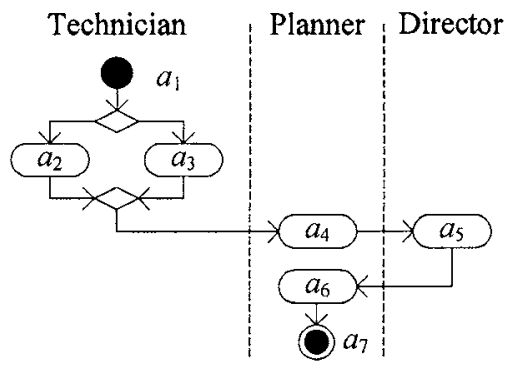

Fig. 6. UML activity diagram model after BPR

\begin{tabular}{|c|c|c|c|c|c|}
\hline & $F_{1}$ & $F_{2}$ & $F_{3}$ & $F_{4}$ & $F_{\mathrm{s}}$ \\
\hline$\left(a_{1}, a_{2}\right)$ & & & & 1 & \\
\hline$\left(a_{1}, a_{3}\right)$ & & & & 1 & \\
\hline$\left(a_{2}, a_{4}\right)$ & & & & & 1 \\
\hline$\left(a_{3}, a_{4}\right)$ & & & & & 1 \\
\hline$\left(a_{4}, a_{5}\right)$ & 1 & & & & \\
\hline$\left(a_{5}, a_{6}\right)$ & 1 & & & & \\
\hline$\left(a_{6}, a_{7}\right)$ & 1 & & & & \\
\hline
\end{tabular}

Fig. 7. PS contour matrix model after BPR

Using the path-searching algorithm of business process mode, two activity paths are found out as follows:

$$
\mathrm{P}_{1}=\left\{a_{1}, a_{2}, a_{4}, a_{5}, a_{6}, a_{7}\right\}, \mathrm{P}_{2}=\left\{a_{1}, a_{3}, a_{4}, a_{5}, a_{6}, a_{7}\right\}
$$


The time consuming of all activities, the execution probability of the split link and the time consuming of all activity paths are determined as shown in Table 6 .

Table 6. Computing Results of Parameters after BPR

\begin{tabular}{|c|c|c|c|c|c|c|}
\hline $\begin{array}{c}\text { Activity } \\
a_{\mathrm{i}}\end{array}$ & $\begin{array}{c}\text { Time } \\
\text { consuming } \\
t_{\mathrm{i}}\end{array}$ & $\begin{array}{c}\text { Interrelation } \\
F_{\mathrm{k}}\left(a_{\mathrm{i}}, a_{\mathrm{j}}\right)\end{array}$ & $\begin{array}{c}\text { Execution } \\
\text { probability } \\
m_{\mathrm{ij}}\end{array}$ & $\begin{array}{c}\text { Path } \\
P_{\mathrm{v}}\end{array}$ & $\begin{array}{c}\text { Anticipant } \\
\text { time } \\
\text { consuming } \\
T_{v}\end{array}$ & $\begin{array}{c}\text { Anticipant } \\
\text { execution } \\
\text { probability } \\
p_{\mathrm{v}}\end{array}$ \\
\hline $\overrightarrow{a_{1}}$ & 0 & \multirow{4}{*}{$F_{4}\left(a_{1}, a_{2}\right)$} & \multirow{4}{*}{0.9} & \multirow{4}{*}{$P_{1}$} & \multirow{4}{*}{32} & \multirow{4}{*}{0.9} \\
\hline$a_{2}$ & 10 & & & & & \\
\hline$a_{3}$ & 5 & & & & & \\
\hline$a_{4}$ & 10 & & & & & \\
\hline$a_{5}$ & 4 & \multirow[t]{2}{*}{$F_{4}\left(a_{1}, a_{3}\right)$} & \multirow[t]{2}{*}{0.1} & \multirow[t]{2}{*}{$P_{2}$} & \multirow[t]{2}{*}{27} & \multirow[t]{2}{*}{0.1} \\
\hline $\begin{array}{l}a_{6} \\
a_{7}\end{array}$ & $\begin{array}{l}8 \\
0\end{array}$ & & & & & \\
\hline
\end{tabular}

The anticipant time consuming of business process after modifying is computed as follows:

$$
Z_{2}=\sum_{\nu=1}^{2} T_{v} p_{v}=(32 \times 0.9+27 \times 0.11)=31.5
$$

We can see that there is no activity loop in the new business process of spare parts requisition and that the anticipant time consuming of the business process is reduced from 62.1 to 31.5 .

\section{Conclusions}

Reconfigurability is one of the intelligent characteristics of enterprise information system. In the paper, a new business process reconfiguration method for enterprise information system is proposed. It unites UML and polychromatic sets theory and has a well-defined mathematical foundation and an easy-to-understand graphical feature. Using the proposed method, business process is analyzed quantitatively and the key bottlenecks and improvement opportunities are identified to reconfigure the business process for enterprise information system. An enterprise information subsystem of spare parts requisition is used to illustrate the effectiveness of the proposed method. Results show that business process reconfiguration can reduce the cost and improve efficiency remarkably and enterprise information system is reconfigurable enough to rapid changes. 


\section{References}

1. J.K.C. Ng, W.H. Ip, and T.C. Lee, The Development of an Enterprise Resources Planning System Using a Hierarchical Design Pyramid, Journal of Intelligent Manufacturing 9(5), 385399 (1998).

2. C. Konstantinos and C. Theodora, ERP based business process reengineering in a human resources department: a case study approach, In the Proceedings of the Sixth International Conference of Enterprise Information Systems (ICEIS'04), edited by I. Seruca, J. Filipe, S. Hammoudi and J. Cordeiro (INSTICC, Setubal, 2004), pp. 78-83.

3. T. Petros, A DSS Model that Aligns Business Strategy and Business Structure With Advanced Information Technology: A Case Study, Annals of Cases on Information Technology 6, 157-175 (2004).

4. M. Hammer and J. Champy, Reengineering the Corporation: A Manifesto for Business Revolution (HarperCollins Publishers, New York, 1993).

5. V. Grover, K.D. Fiedler, and J.T.C. Teng, Exploring the Success of Information Technology Enabled Business Process Reengineering, IEEE Transactions on Engineering Management 41(3), 276-284 (1994).

6. H. Shen, B. Wall, M. Zaremba, Y. Chen, and J. Browne, Integration of Business Modeling Methods for Enterprise Information System Analysis and User Requirements Gathering, Computer in industry 54(3), 307-323 (2004).

7. R.S. Aguilar-Saven, Business Process Modeling: Review and Framework, International Journal of Production Economics 90(2), 129-149 (2004).

8. Y. Wei and S. Zhang, Modeling Workflow Using UML Activity Diagram, High technology letters 10(2), 61-64 (2004).

9. Y. Xiao, F. Xu, and W. Hu, Business Process Reengineering Based on IDEF Methods, In the Proceedings of the IEEE International Conference of Information Reuse and Integration (IRI-2004), edited by A.M. Memon and N. Zhao (IEEE, New York, 2004), pp. 265-270.

10. V.V. Pavlov, Polychromatic Sets and Graphs for CALS (STANKIN Press, Moscow, 2002).

11. L. Xu, Z. Li, S. Li, and F. Tang, A Polychromatic Sets Approach to Conceptual Design of Machine Tools, International Journal of Production Research 43(12), 2397-2421 (2005).

12. Z. Li and L. Xu, Polychromatic Sets and its Application in Simulating Complex Objects And Systems, Computers and Operations Research 30(6), $851-860$ (2003).

13. Z. Li, Research and Application of Polychromatic Sets in Advanced Manufacturing (China WaterPower Press and Knowledge Press, Beijing, 2005).

14. M. Fowler (Translated by J. Xu), UML Distilled: A Brief Guide to the Standard Object Modeling Language (Tsinghua University Press, Beijing, 2005).

15. R. France, A. Evans, K. Lano, and B. Rumpe, The UML as a Formal Modeling Notation, Computer Standards \& Interfaces 19(7), 325-334 (1998)

16. W. van der Aalst and K. van Hee (Translated by J. Wang and L. Wen), Workflow management: models, methods and systems (Tsinghua University Press, Beijing, 2004).

17. Dingwei Wang, Zhiwen Tang, W.H. IP, and Richard Y.K. Fung, A Human-Computer Interactive Approach Based on Activity-Section Analysis for BPR, Production Planning \& Control 11(8), 789-796 (2000). 